\title{
(2) OPEN ACCESS \\ Use of coronary stent grafts for the treatment of high-flow carotid cavernous fistula
}

\author{
Ivo Petrov, ${ }^{1}$ Zoran Stankov, ${ }^{1}$ Damyan Boychev 다, ${ }^{1}$ Marko Klissurski ${ }^{2}$
}

${ }^{1}$ Cardiology, Angiology and Electrophysiology, Acibadem City Clinic Cardiovascular Center, Sofia, Bulgaria ${ }^{2}$ Neurology, Acibadem City Clinic cardiovascular Center, Sofia, Bulgaria

\section{Correspondence to}

Professor Ivo Petrov; petrovivo@hotmail.com

Accepted 30 October 2021
Check for updates

(C) BMJ Publishing Group Limited 2021. Re-use permitted under CC BY-NC. No commercial re-use. See rights and permissions. Published by BMJ.

To cite: Petrov I, Stankov Z, Boychev D, et al. BMJ Case Rep 2021;14:e245922. doi:10.1136/bcr-2021245922

\section{SUMMARY}

Carotid cavernous fistulas are abnormal communications between the carotid artery or its branches and the cavernous sinus. It can be traumatic or spontaneous. The widely accepted treatment is by detachable balloons. Advancements in the field of endovascular medicine made available other options for the treatment of this condition. Covered stents are widely available and offer preservation of the parent artery while occluding the fistula.

\section{BACKGROUND}

The carotid cavernous fistula (CCF) could cause life-threatening bleeding, and the endovascular management is considered to be the gold standard. Thanks to improvements in techniques and devices in recent years, covered stents provide a widely available alternative treatment option for the CCF. Further data are needed about the neuroendovascular usefulness of the covered stents.

\section{CASE PRESENTATION}

A 20-year-old man was transferred to our clinic for the treatment of life-threatening CCF. The patient had suffered a car accident a month earlier and has been in coma and on ventilator since. He had skull base fractures on both sides in the basal temporal region, fracture of petrous part of the right temporal bone, fractures of the right zygomatic bone, right part of the maxilla, and blood collections in the maxillary, ethmoidal and sphenoidal sinus. CT of the head had visualised a CCF on the right side. Since the crash, the patient has had several episodes of profuse bleeding from both ears and the nose. They were managed conservatively with placement of temporary tamponade. He required more than 10 hemotransfusions during the hospital stay.

On presentation, the patient was in severe general condition, intubated but with normal vital signs (HR 84 bpm, blood pressure 123/77 mm Hg). He had a quite tense right eye proptosis. The left eye was spontaneously opened. Glasgow-Liege Coma Scale (GLCS) Score was 11. The left corneal and glabellar (frontalorbicular) reflex were absent. The direct pupillary reaction to light was preserved as well as oculocephalic reflexes. A quadriparesis with spastic paralysis of the left arm, anisoreflexia and bilateral negative Babinski's signs were evident. On pain stimulation, there was minimal flexor response in the right limbs. The head was deviated to the right side, with spontaneous mild movements. Verbal contact was missing.

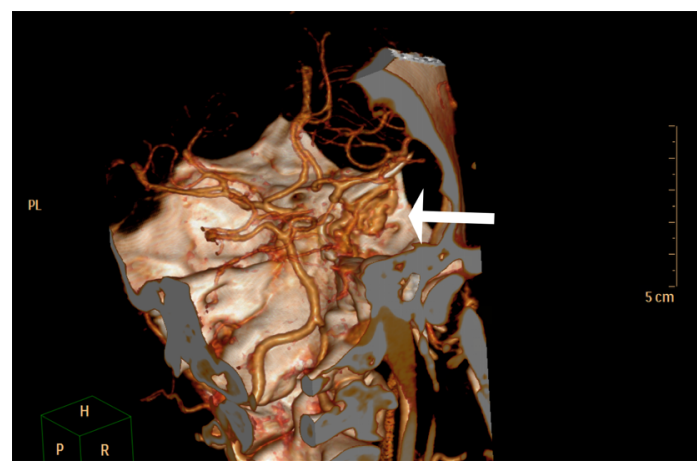

Figure 1 Three-dimensional reconstruction of the intracranial vessels - carotid cavernous fistula is visualised in the right cavernous sinus.

\section{INVESTIGATIONS}

The CT scan on presentation confirmed the previously described bone fractures, CCF and multiple old haemorrhagic contusions in the right temporal, frontal and parietal zones (figure 1). The right superior ophthalmic vein was dilated up to $7.5 \mathrm{~mm}$, the right inferior ophthalmic vein was dilated up to $2.6 \mathrm{~mm}$. Due to the high-flow CCF and the backflow into the ophthalmic veins, the right facial vein was arterialised and visible on the three-dimensional angioreconstruction (figure 2). The CCF was classified as traumatic high-flow fistula type A.

MRI scan on admission showed multiple small haemorrhagic contusions in the right hemisphere of the brain and cerebellum, which have greatly reduced in size compared with the MRI 3 weeks earlier. In this case, we see multiple lesions in the cerebrum, cerebellum and brainstem with perivascular haemorrhages, contusions and lacerations of the brain parenchyma with necrotic, dystrophic and oedematous changes, which all lead to damage to the upper right motor neuron and the right

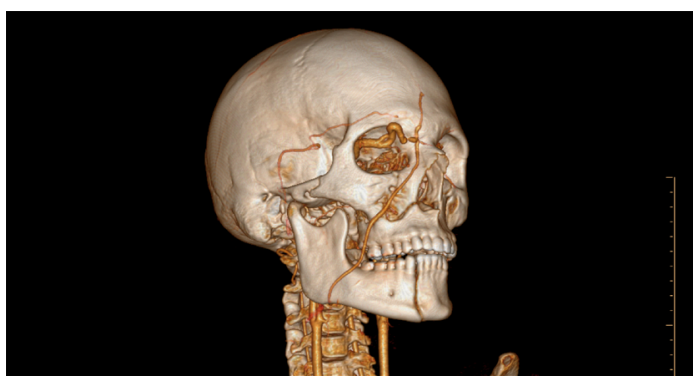

Figure 2 Three-dimensional reconstruction of ophthalmic veins - the greatly dilated superior ophthalmic vein is visualised, draining into the right facial vein, both arterialised by the high-flow fistula. 


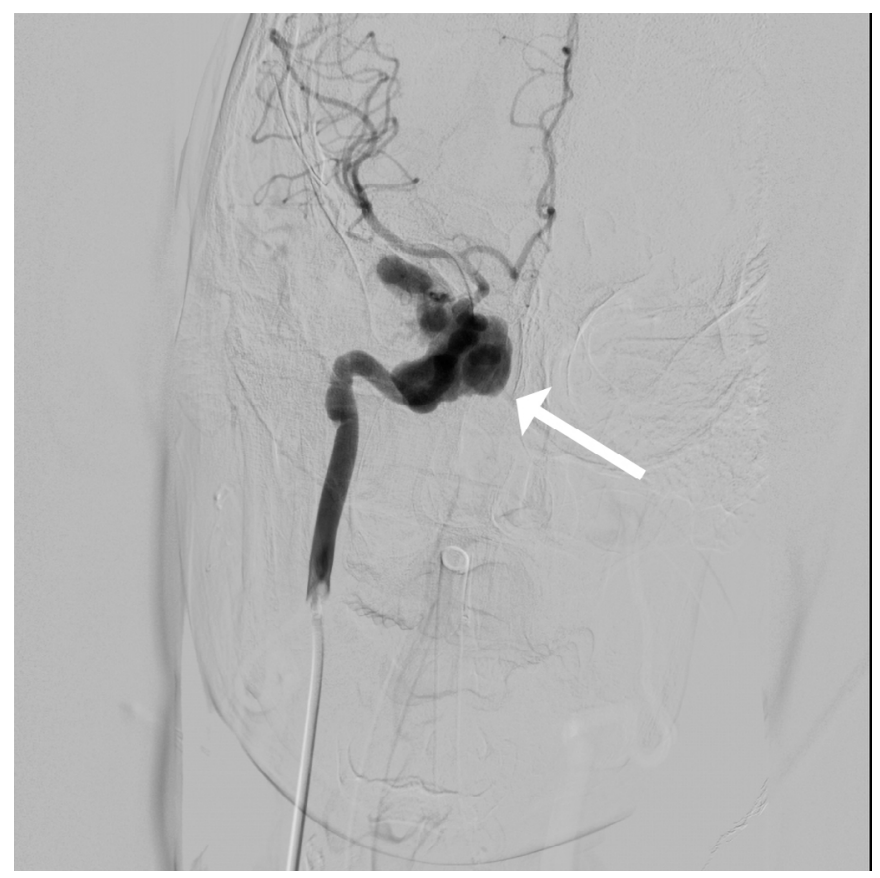

Figure 3 Diagnostic cerebral angiography_high-flow carotid cavernous fistula is visualised.

abducens nerve. The upper motor neuron syndrome may or may not be accompanied by the Babinski sign. The sing itself simply implies a pyramidal tract lesion and may not be associated with any of the upper motor neuron signs, which are extrapyramidal in origin (weakness, spasticity, clonus, hyperreflexia). The lesion in the right part of the cerebellum is responsible of the ataxia in the right limbs and the contusion in the right hemisphere and the brainstem are responsible for the weakness, hyperreflexia in the right limbs plus the central lesions of the facial nerve.

\section{TREATMENT}

Using right femoral approach, a diagnostic angiography was performed, revealing the CCF on the right side (figure 3 and video 1). The angio confirmed that the diagnosis of high-flow CCF type A. There was neither arterial steal, nor the fistula affected the rest of the arterial intracranial circulation in any
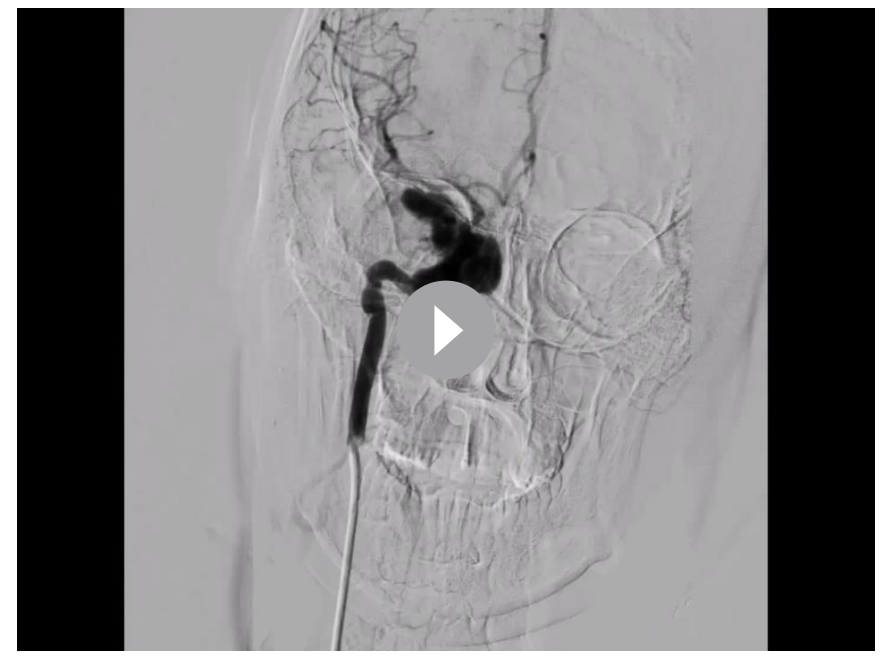

Video 1 Diagnostic cerebral angiography—high-flow carotid cavernous fistula is visualised

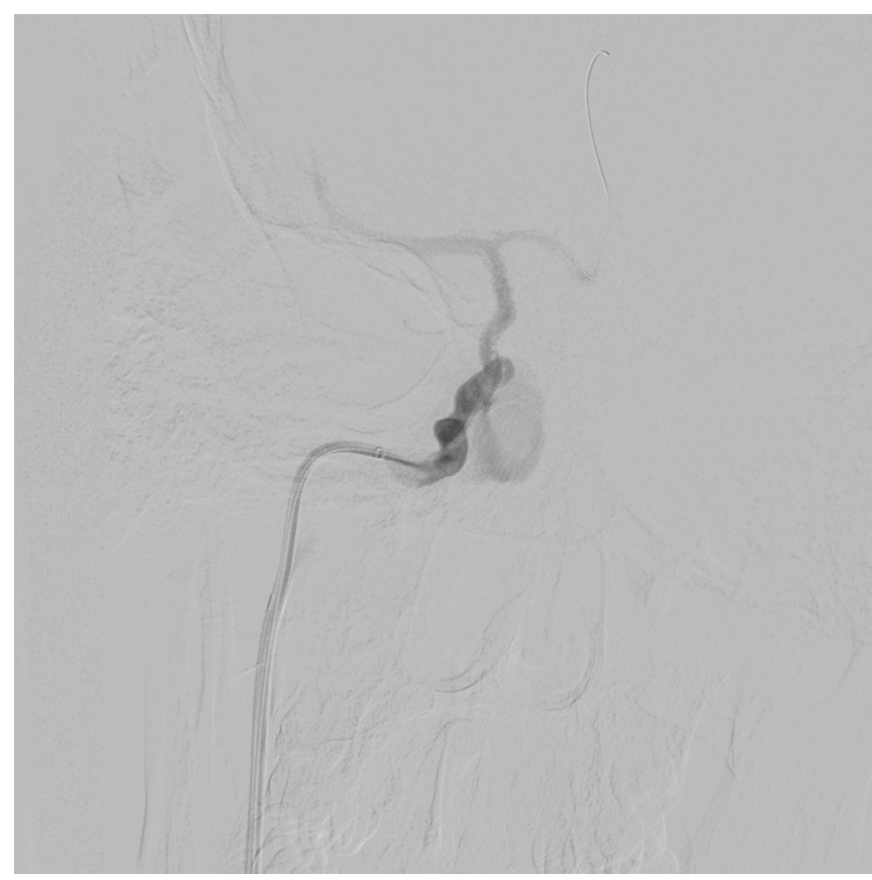

Figure 4 Stent graft positioning - the covered stent position is confirmed using subtraction.

way. The diagnostic catheter was exchanged for a $90 \mathrm{~cm} 6 \mathrm{~F}$ Flexor Shuttle Guiding Sheath (Cook medical, USA). A 0.014 Runthrough NS PTCA guide wire (Terumo, Japan) was positioned in the distal part of anterior cerebral artery and the long sheath was placed in the right internal carotid artery (ICA), as high as possible. A guiding catheter was placed just below in CCF. Two covered stents, PK Papyrus 3.0/20 mm (Biotronik, Germany) and PK Papyrus $3.5 / 20 \mathrm{~mm}$, were consecutively implanted in the ICA, covering the fistula orifice (figures 4 and 5 ; videos 2 and 3). Small residual filling of the fistula was visualised (figure 6

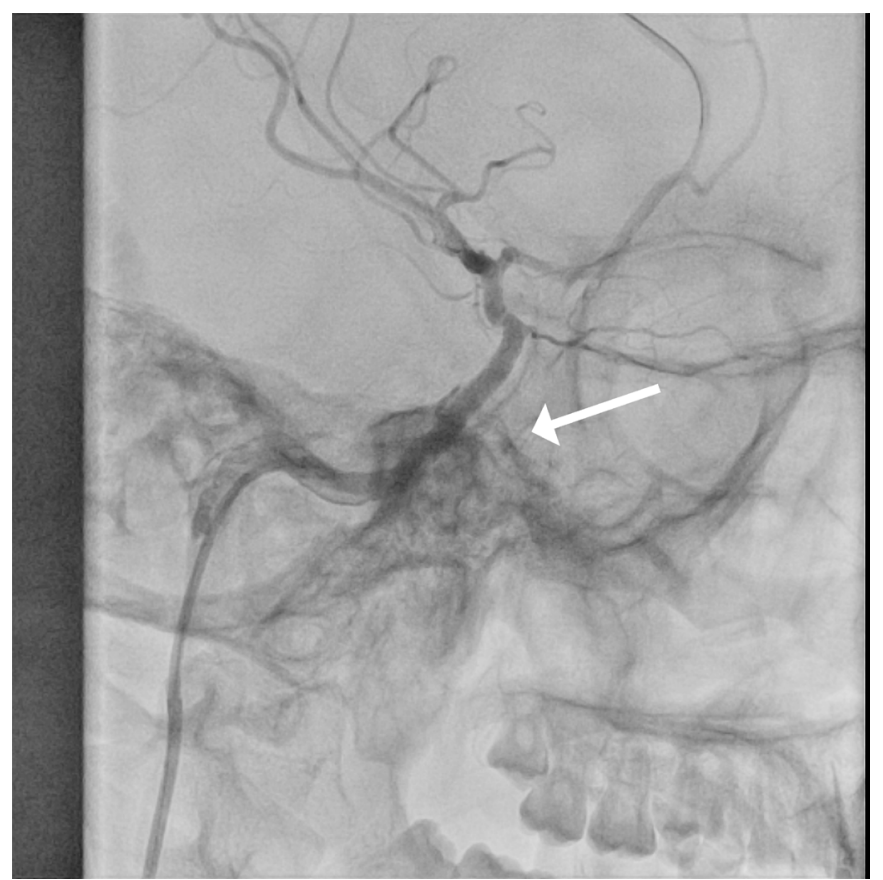

Figure 5 Fluoroscopy after covered stent 1 implantation-residual filling of the fistula is present from entry point proximal to the stent. 

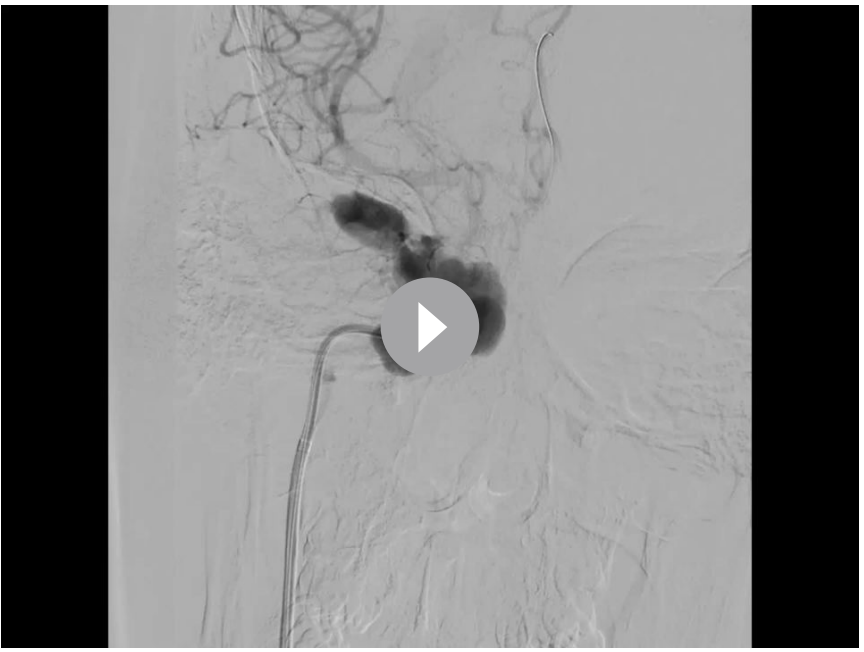

Video 2 Stent graft positioning - the covered stent position is confirmed using subtraction

and video 4) and post dilation with NC Sprinter $4.0 / 20 \mathrm{~mm}$ (Medtronic, Ireland) was performed with excellent final result (figures 7-9, videos 5 and 6). Neither artery straightening nor vessel spasm was evident at the end of the procedure. The patient received dual antiplatelet therapy after the procedure as is the in-hospital protocol in such procedures. The patient was started on aspirin $100 \mathrm{mg}$ once daily and clopidogrel $75 \mathrm{mg}$ once daily for 1 year, followed by the discontinuation of clopidogrel.

The tamponades in the ears and nose were removed 6 hours after the procedure with no residual bleeding. Previous attempts to remove the tamponade have led to recurrent severe episodes of epistaxis. We must emphasise that this time the patient was even receiving dual antiplatelet therapy, which furthermore gave us confidence that the fistula was isolated. The patient was kept in induced coma after which he was extubated and gradually started rehabilitation. The neurological status on discharge 2 months after the admission was significantly improved with GLCS of 15. The right eye exophthalmos/proptosis was significantly reduced. The patient was able to execute elementary commands and to move even to a limited extent his right limbs with ataxia. The left spastic paresis remained as well as moderate right abducens nerve lesion and left central facial palsy.

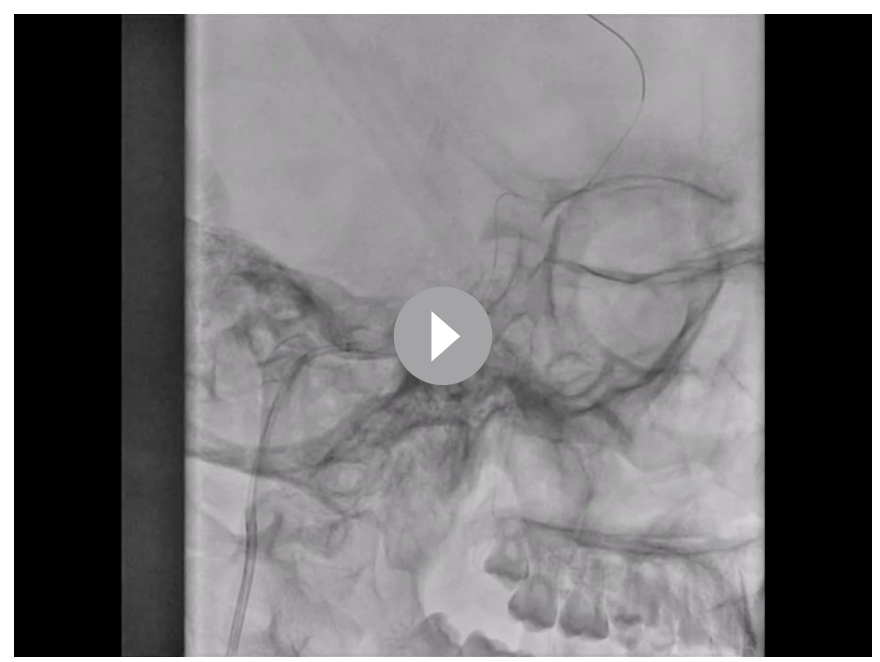

Video 3 Fluoroscopy after covered stent 1 implantation-residual filling of the fistula is present from entry point proximal to the stent

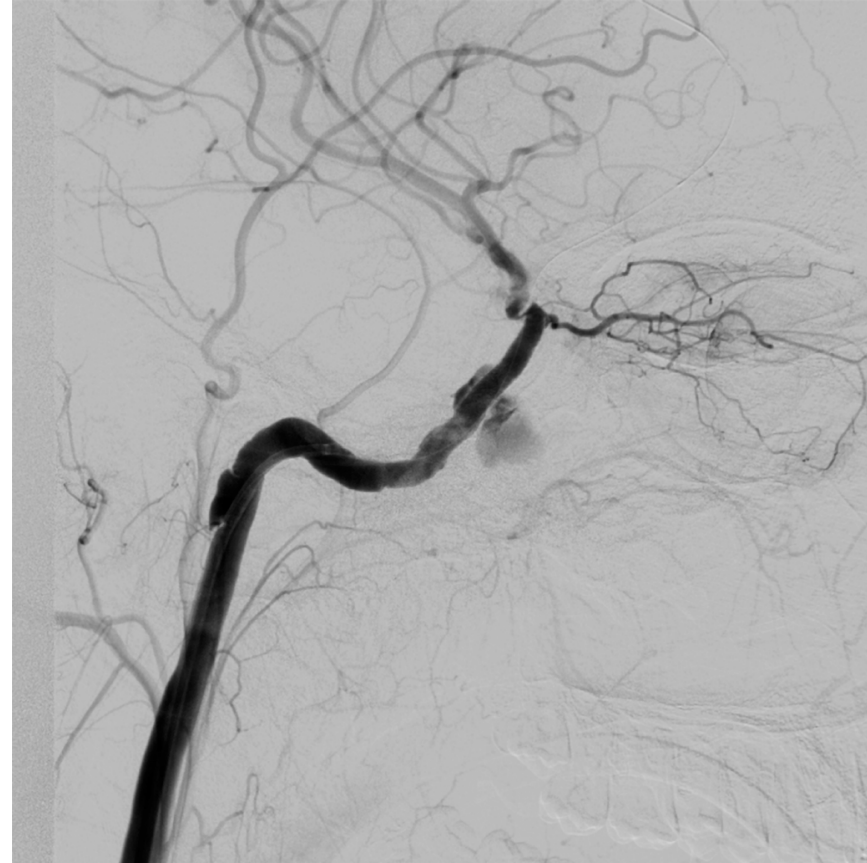

Figure 6 Fluoroscopy after implantation of the second stentendoleak was identified on the control fluoroscopy. The entry point was at the level of stents overlap.

\section{OUTCOME AND FOLLOW-UP}

In the 12-month follow-up period, no bleeding of embolic incidents. There has been a great progress in the rehabilitation of the patient, with improvement of both his motor and speaking skills.

\section{DISCUSSION}

In 1985, Barrow et al published a classification of CCFs by their anatomical location on angiography. CCF was divided into four categories: type A fistula-a direct communication between the ICA and the cavernous sinus (CS), type B-between the meningeal branches of ICA and the CS, type C-between meningeal branches of the external carotid artery and the CS and type $\mathrm{D}$-between the meningeal arteries of both carotid arteries and the CS. ${ }^{1}$ The CCF can also be classified as direct (type A) and
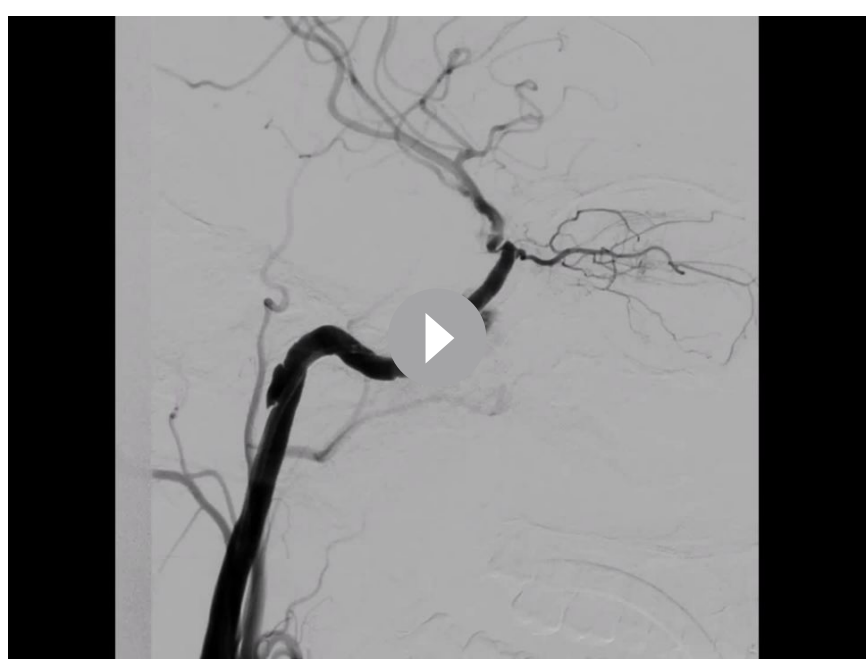

Video 4 Fluoroscopy after implantation of the second stentendoleak was identified on the control fluoroscopy. The entry point was at the level of stents overlap 


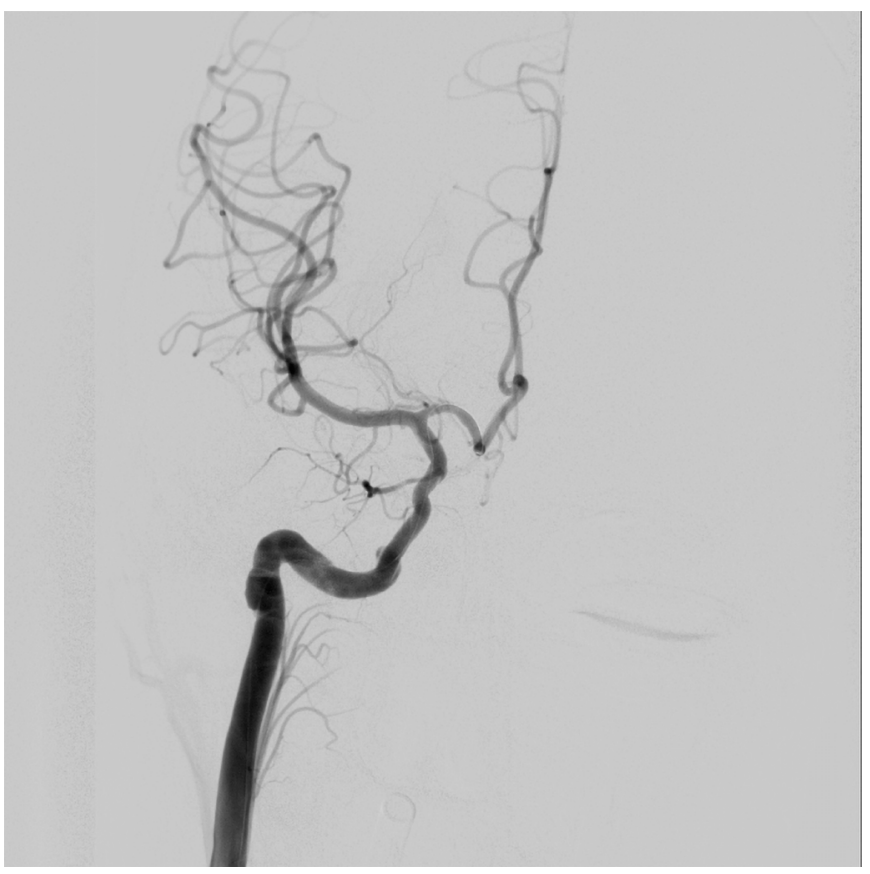

Figure 7 Final fluoroscopy showed patent's internal carotid artery and completely isolated fistula. Left oblique projection.

indirect (types B, C and D), low-flow and high-flow, traumatic and spontaneous. ${ }^{1}$

The most common presentations of CCF are proptosis of the eye on the ipsilateral side of the fistula, cephalic bruit, headache, diminished visual acuity and conjunctival chemosis. ${ }^{2}$ The typical presentation of a type A CCF is the development of Dandy's triad-exophthalmos, bruit and conjunctival chemosis. Otorrhagia and epistaxis may be seen in up to $3 \%$ of the cases of CCF. $^{3}$

The superior and inferior veins of the eye both drain into the CS, the high-flow fistulas increase the pressure in the CS and cause backflow into the ophthalmic veins, leading to stasis of blood in the eye. That may cause proptosis, episcleral and

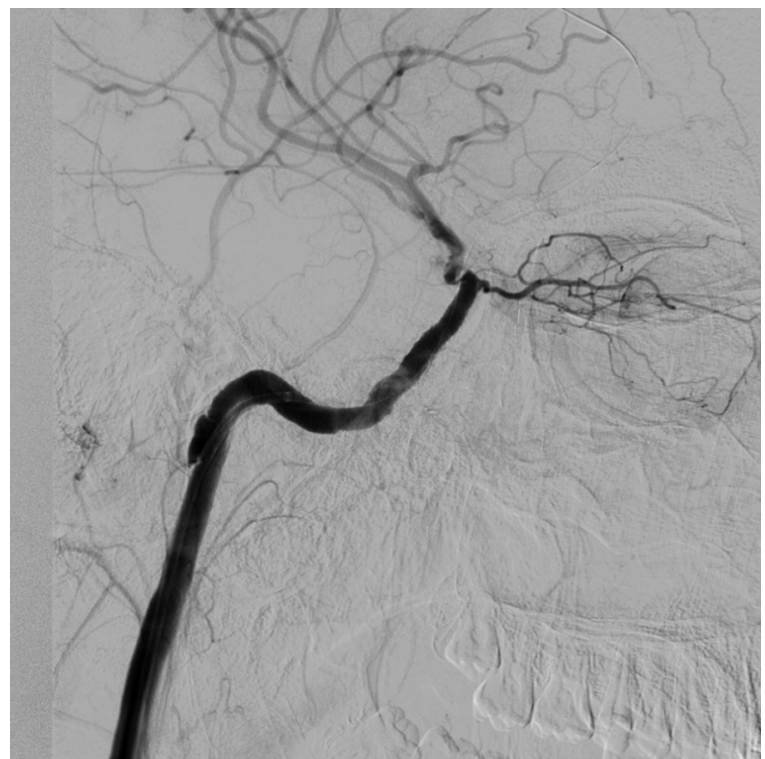

Figure 8 Final fluoroscopy showed patent's internal carotid artery and completely isolated fistula. Right oblique projection.

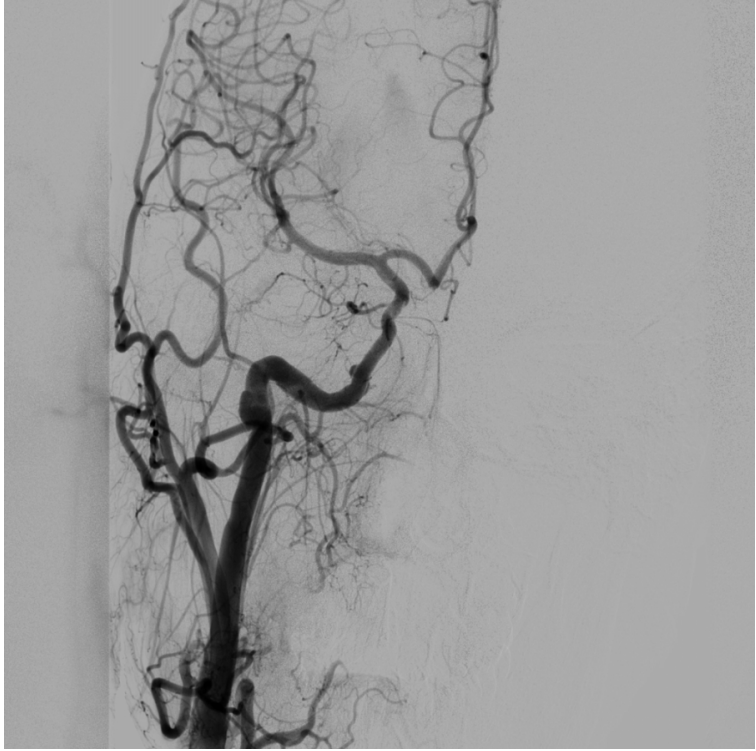

Figure 9 Final fluoroscopy showed patent's internal carotid artery and completely isolated fistula. Left cranial projection.

conjunctival arterialisations, and enlargement of the extraocular muscles. Increased episcleral pressure and venous pressure may result in elevated intraocular pressure and secondary glaucoma. ${ }^{4}$

A spontaneous resolution of high-flow CCF has been described in the literature but it is extremely rare. Clinical signs such as increased intracranial pressure, rapidly progressive proptosis, haemorrhage, diminished visual activity and transient ischaemic attacks are associated with poor prognosis and warrant emergent and aggressive interventional treatment to improve outcome. ${ }^{5}$

The first endovascular treatment of CCF with a detachable balloon done by Serbinenko was described in $1974 .{ }^{6}$ Since the 1980s, this has been the golden standard for the treatment of CCFs. Due to advancement in endovascular devices and techniques, and the unavailability of detachable balloons in recent years, coils, alcohol and stent graft embolisation of CCF have been an emerging treatment options. ${ }^{5}$

The endovascular treatment options of type A CCF device mainly in two groups-transarterial and transvenous. Different
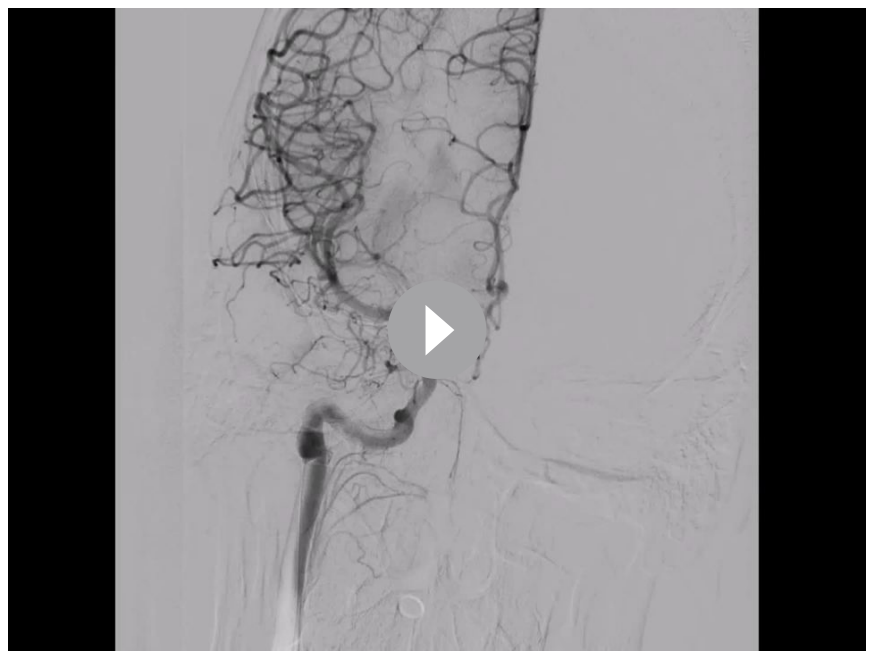

Video 5 Final fluoroscopy left oblique projection - final fluoroscopy showed patent's internal carotid artery and completely isolated fistula. Neither artery straightening nor spasm is evident 


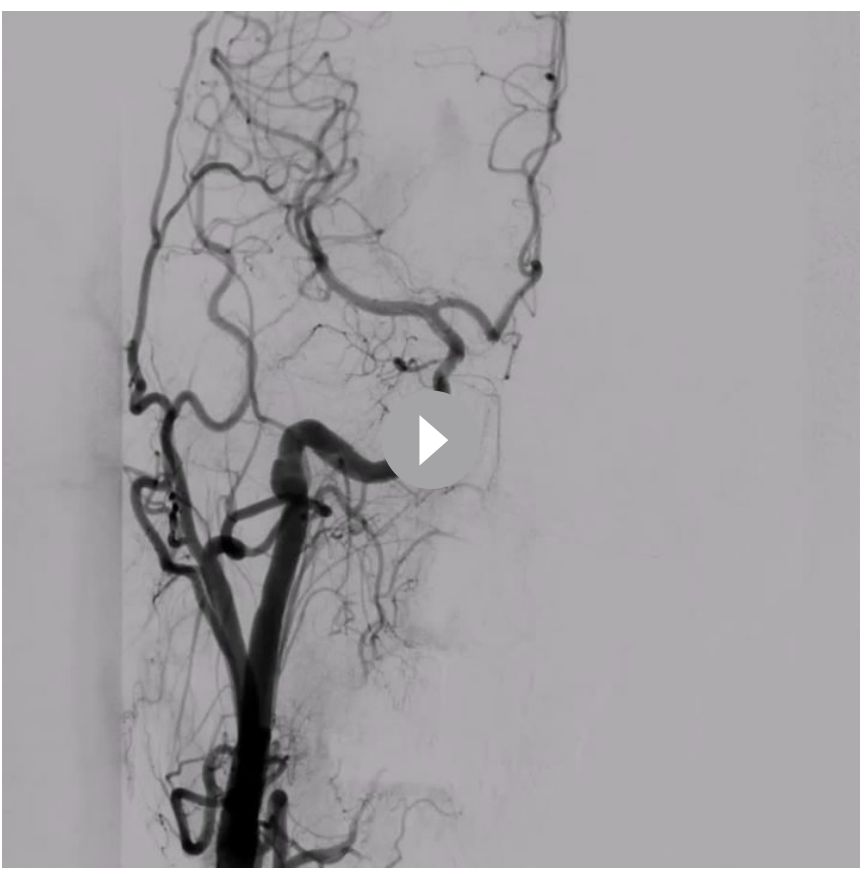

Video 6 Final fluoroscopy left cranial projection-final fluoroscopy showed patent's internal carotid artery and completely isolated fistula. Neither artery straightening nor spasm is evident

sources give different data, which one is the preferred method but anyway endovascular repair has excellent results. Besides stent grafts, the another transarterial options are placement of detachable balloons, placement of coils or use of ethylene vinyl alcohol copolymer (EVOH) to occlude the direct communication. The coils or balloons may migrate through the defect into the parent vessel if it the tear is big enough (like in our case), potentially causing brain ischaemia. The transvenous approach can be used as a main one or when the ICA cannot be accessed due to traumatic injury, severe tortuosity or inability to catheterise the tear. The route to the CCF in this case goes usually through the internal jugular vein and the inferior petrosal sinus. The goal is to discontinue the venous outflow from the CS using coils or liquid embolic agents. In both transarterial and transvenous approach, there are a number of times when coils are not enough for the full embolisation of the fistula and $\mathrm{EVOH}$ or Onyx is used as an additional agent in order to penetrate and fully occlude the communication. Because of the wide orifice of the fistula and the hugely dilated superior ophthalmic vein, we estimated the risk of coil migration as high. Transvenous approach was planned as a backup option in case of failure of the transarterial approach due to the high risk of coil migration and the lack of experience of our team with this approach for intracranial procedures. Embolisation with Onyx (Medtronic, Ireland) was considered but due to insufficient experience of our team with it and the hazard of postembolisation CS thrombosis and swelling, we deemed it inappropriate. ${ }^{7}$ We choose to repair the vessel defect with stent graft PK Papyrus deployment as our main strategy.

The four largest studies to date of CCF, treated with stent graft, involve a total of 25 patients and report excellent results with mean follow-up of 12 months and $84 \%$ patency of the ICA. ${ }^{8-11}$ Covered stents are widely available, offered in a great range of sizes and offer the possibility of ICA patency preservation, while sealing the fistula. The main problem of these covered stents is the fact that they are still not approved for intracranial use in some neurological conditions. Another disadvantage is the limited flexibility of the graft, complicating their navigation through the tortuous anatomy of the intracranial vessels and also the risk of 'straightening' of the artery. The stent we used (PK Papyrus) offers improved flexibility thanks to its single stent design and made possible the perfect final result we managed, without any straightening of the artery at the end.

A problem of the Onyx and coil treatment of CCF is the mass effect. Fewer mass effects have been observed with stent graft compared with coils and Onyx in the treatment of cerebral aneurysms. ${ }^{12}$ Aneurysms treated with covered stents have greatly reduced recurrence rates compared with those treated with coils or liquid embolic materials. ${ }^{12}$ Additional data are needed to see if the same applies for the CCFs.

\section{Patient's perspective}

Patient perspective - I am greatly thankful to everyone involved in my treatment. I am fully motived continue rehabilitation until I get back to my old self.

Family's perspective-We cannot imagine our life right now if our son has not received the treatment, he did. Without the fully committed staff of the hospital, we would not be where we are. After the procedure, the condition of our son improved minute by minute and eventually, he was out of come, which gave is hope that everything will be OK. We believe that with active rehabilitation he can go back to his life.

\section{Learning points}

- Carotid cavernous fistulas can be a life-threatening condition.

- Covered stents are a feasible treatment option for CCF.

- Approved neuroendovascular covered stent and additional data are warranted.

- Double antiplatelet therapy after stenting was not causing problems in this patient with post-traumatic and haemorrhagic brain injuries, and previous severe cranial bleeding.

Contributors All of the authors have contributed equally to the manuscript, and it was a team effort where everybody was engaged with everything but formally, we can divide the contribution in the following manner: ISP and ZIS - planning, conduct, conception and design. DB - reporting, acquisition and interpretation of data. MKneuro consult and reporting.

Funding The authors have not declared a specific grant for this research from any funding agency in the public, commercial or not-for-profit sectors.

Competing interests None declared.

Patient consent for publication Consent obtained directly from patient(s).

Provenance and peer review Not commissioned; externally peer reviewed.

Open access This is an open access article distributed in accordance with the Creative Commons Attribution Non Commercial (CC BY-NC 4.0) license, which permits others to distribute, remix, adapt, build upon this work non-commercially, and license their derivative works on different terms, provided the original work is properly cited and the use is non-commercial. See: http://creativecommons.org/ licenses/by-nc/4.0/.

Case reports provide a valuable learning resource for the scientific community and can indicate areas of interest for future research. They should not be used in isolation to guide treatment choices or public health policy.

\section{ORCID iD}

Damyan Boychev http://orcid.org/0000-0002-7263-8308 


\section{REFERENCES}

1 Barrow DL, Spector RH, Braun IF, et al. Classification and treatment of spontaneous carotid-cavernous sinus fistulas. J Neurosurg 1985;62:248-56.

2 Ringer AJ, Salud L, Tomsick TA. Carotid cavernous fistulas: anatomy, classification, and treatment. Neurosurg Clin N Am 2005;16:279-95.

3 Halbach VV, Hieshima GB, Higashida RT, et al. Carotid cavernous fistulae: indications for urgent treatment. AJR Am J Roentgenol 1987;149:587-93.

4 Chaudhry IA, Elkhamry SM, Al-Rashed W, et al. Carotid cavernous fistula: Ophthalmological implications. Middle East Afr J Ophthalmol 2009;16:57.

5 Korkmazer B, Kocak B, Tureci E, et al. Endovascular treatment of carotid cavernous sinus fistula: a systematic review. World J Radiol 2013;5:143.

6 Serbinenko FA. Balloon catheterization and occlusion of major cerebral vessels. J Neurosurg 1974;41:125-45.
7 Elhammady MS, Wolfe SQ, Farhat $\mathrm{H}$, et al. Onyx embolization of carotid-cavernous fistulas. J Neurosurg 2010;112:589-94.

8 Tiewei Q, Ali A, Shaolei G, et al. Carotid cavernous fistulas treated by endovascular covered stent grafts with follow-up results. Br J Neurosurg 2010;24:435-40.

9 Gomez F, Escobar W, Gomez AM, et al. Treatment of carotid cavernous fistulas using covered stents: midterm results in seven patients. AJNR Am J Neuroradiol 2007;28:1762-8.

10 Archondakis E, Pero G, Valvassori L, et al. Angiographic follow-up of traumatic carotid cavernous fistulas treated with endovascular stent graft placement. AJNR Am J Neuroradiol 2007;28:342-7.

11 Choi BJ, Lee TH, Kim CW, et al. Endovascular graft-stent placement for treatment of traumatic carotid cavernous fistulas. J Korean Neurosurg Soc 2009;46:572.

12 Fang C, Liu C-S, Xiao Y-P, et al. Using a covered stent for large cerebral aneurysms treated with stent-assisted coiling. Interv Neuroradiol 2015;21:317-24.

Copyright 2021 BMJ Publishing Group. All rights reserved. For permission to reuse any of this content visit https://www.bmj.com/company/products-services/rights-and-licensing/permissions/

BMJ Case Report Fellows may re-use this article for personal use and teaching without any further permission.

Become a Fellow of BMJ Case Reports today and you can:

- Submit as many cases as you like

Enjoy fast sympathetic peer review and rapid publication of accepted articles

- Access all the published articles

Re-use any of the published material for personal use and teaching without further permission

Customer Service

If you have any further queries about your subscription, please contact our customer services team on +44 (0) 2071111105 or via email at support@bmj.com.

Visit casereports.bmj.com for more articles like this and to become a Fellow 